\title{
An Evolutionary View on Guided Tissue Engineering - from the Replacement to the Regeneration of Damaged Tissue
}

\section{Christoph Brochhausen* and C. James Kirkpatrick}

REPAIR-Lab, Institute of Pathology, European Institute of Excellence on Tissue Engineering and Regenerative Medicine, University Medical Centre of the Johannes Gutenberg-University, Germany

Tissue Engineering represents an interdisciplinary field of science, which brings together Life science and Engineering. Originally understood as a primarily biomaterial driven discipline, today it is generally accepted that Tissue Engineering is a highly complex field, in which biomaterial science, life science and engineering interact to find new strategies for important clinical applications.

From a historical point of view, an interesting evolution took place in which some paradigm shifts give evidence for the tremendous change in our understanding of health and disease. In ancient time during the concept of animistic medicine, not only the assistance of healing but also the use of engineering when healing was not successful is known for long time: even from Neolithic times it has been described that bone fractures were healed obviously by use of bares, and even more interesting, already at that time patient care should be established. It is interesting to realize that even within animistic medicine; the use of different materials was already applied to cure patients. In addition to the use of bares to stabilize various fractures, also highly interventional procedures such as trephinations are documented from all over the world; surprisingly there is evidence that such patients could survive these procedures, without any anesthetic or antiseptic aid [1]. Even if the intention of such procedures were almost animistic, there is evidence that at least some trephinations were performed for medical reasons, in our recent understanding [2]. However, in general, the reasons for such interventions are not in line with our modern anatomic or anatomic-pathological viewpoint. This changed with the use of prosthesis to treat amputations, which are documented from the time of ancient Egyptians. Even if animistic medicine was always the leading concept in the understanding of health and disease, the use of limb prostheses after amputation, played an important role in giving back the anatomical shape, the social and psychological wellbeing, as well as the physiological function, the latter more or less successful [3]. The use of limb prostheses marked the important shift to the paradigm of replacement of damaged or loss tissue by materials. Such replacements are also documented in the dental field, even if there is an ongoing debate regarding the intention and the authenticity of metal fillings, or inlays within the jaw in ancient cultures $[4,5]$. Especially, the development of the prostheses of the upper limbs with mechanical constructions to enable movement of the prosthetic fingers, demonstrates the great efforts which were done to optimize the functional performance of prosthesis, during the Middle-Age. An important issue for the performance of these replacement strategies was represented by the proper and save fixation of the prosthesis to the body, and the interference between the prostheses material and the tissue of the stump.

During the following centuries, a real revolution took place which leads to the development of our modern scientific based medicine. However, some crucial questions remained unsolved, namely the replacement of damaged tissue, the interface between prosthesis, and the human body and their functionality. In this historical context, material science has become an applied science, as generally a clinical application represents the aim of research activity. From the biomaterial viewpoint, the material based replacement of damaged tissues and organs still bared the problem of functionality, even if biomaterial properties were adopted and the amount of materials needed for replacement- strategies were diminished. From the biological point of view, biocompatibility represents one of the most important issues in the evaluation of the performance of implanted biomaterials, regardless, if they are limb prostheses, plates for fracture healing or vascular stents. However, the field of biocompatibility deals always with the borderline between the body and the implant, and measures the range of foreignness or cytotoxicity of the implant, which means that there will be an interface between the body and the material which may avoid proper integration in the body. Therefore, great efforts were made within the last two decades to provide materials with improved biocompatibility, durability and expanded clinical applications [5]. Not only in hard tissue like bone but also in soft tissue replacement, such as the matrix assisted autologous chondrocyte transplantation, the interface between the implant and the unaffected cartilage remains evident, which is reflected by the fact that the long-term clinical outcome is dependent from patient-specific and defect-specific factors [6].

The change from the absence of cytotoxicity, which was given by optimal biocompatibility to the demand of biofunctionality, marked a further paradigm change, which opened innovative perspectives for tissue regeneration due to the biomimetic concept [7]. The term biomimetic concept describes the simulation of natural functions of tissues, especially such functions given by the interplay between structural and functional elements of interfaces in nature. In the biology of such interfaces, components of the extracellular matrix, cells and there products plays an important role, since rearrangements or degradation of extracellular matrix components, several enzymes liberated by the cells, as well as the potential changes of the $\mathrm{pH}$-value in a specific microenvironment take place. In this context, there was a huge challenge for the material science since the biomimetic concept required biodegradable materials that are capable to respond to changes in that microenvironment. The evolution in that direction was given by the development of the so-called smart or biomimetic biomaterials. One key feature of such biomaterials is to capture the degree of

*Corresponding author: Christoph Brochhausen, European Institute of Excellence on Tissue Engineering and Regenerative Medicine, Institute of Pathology, University Medical Centre of the Johannes Gutenberg-University Germany, Tel: ++496131 1773 07; Fax: ++49 6131174773 07; E-mail: brochhausen@pathologie.klinik.uni-mainz.de

Received September 27, 2012; Accepted September 28, 2012; Published October 01, 2012

Citation: Brochhausen C, Kirkpatrick CJ (2012) An Evolutionary View on Guided Tissue Engineering-from the Replacement to the Regeneration of Damaged Tissue. J Tissue Sci Eng 3:e117. doi:10.4172/2157-7552.1000e117

Copyright: () 2012 Brochhausen C, et al. This is an open-access article distributed under the terms of the Creative Commons Attribution License, which permits unrestricted use, distribution, and reproduction in any medium, provided the original author and source are credited. 
complexity needed to mimic the extracellular matrix of nature tissue. Actually, it is an ongoing challenge to design biomaterials which are capable to recreate the molecular architecture of extracellular matrix, including the recreation of the dynamic mechanisms of extracellular matrix response to changes within the microenvironment [8,9]. A second element of the biomimetic concept is not to use biomaterials in a pure state, but with incorporated "trigger"-molecules such as signaling molecules and growth factors, with the aim to create a functional tissue or organ like implant. For this purpose, essential growth factors such as bone morphogenetic proteins are already well known for tissue engineering strategies, which are partly already in clinical application [10]. One important aim of Tissue Engineering in this context, represents the creation of functional tissue like constructs ex vivo, which will be implanted. This development was possible due to the broad scientific activity in the field of bioreactors. Bioreactors enable not only the scientific analyses of tissue like structures under different conditions, but also enable the reliable and standardized synthesis of such tissue like structures in an up-scaled manner, which represent an crucial prerequisite for its clinical use.

With the application of growth factors and signaling molecules, the material-system and its effective application became more complex, because the beneficial effects of such different "trigger"-molecules are dependent on several parameters:

- many of such molecules revealed there effects by interaction with receptors of the target cells, in consequence, the effects are dependent from the receptor expression of these target cells;

- such molecules act in a dose dependent manner, which means that there is an optimal dose for the best effects,

- Such molecules underwent rapid turnover, so that there is sensitivity for their effect given by the half-life of these molecules. Taken these obstacles together it becomes clear, that for the proper use of signaling molecules or growth factors, it is mandatory that the right dose is at the right time at the right place, and most important that the effector cells are present in a sensitive manner. To reach this goal, an entire understanding of the basic mechanisms in interface biology, as well as regeneration and healing is important. In this context, today it is generally accepted that regeneration recapitulates in part developmental processes, which means that it is essential to understand developmental processes, as an important prerequisite for the design of effective biomaterials with incorporated "trigger"-molecules [11]. In our own work, we could demonstrate that the processes of the growth plate of the long bones represent a suitable model for the targeting of potential growth factors, or signaling molecules for tissue engineering purposes [12]. However, with the detection of a potent signaling molecule or growth factor the challenge goes on, because to solve the problems for effective application described above, techniques and methods known from drug delivery should be applied. From this more pharmaceutical point of view, it is important to develop a manner of delivery which allows an optimal dosing, and most important which allows the release of the functional molecule [13]. Furthermore, the stability of the active agent should be analyzed under physiological and storage conditions [14].

The third element of modern tissue engineering strategies is represented by the cellularity of the biomaterial, primarily given by autologous cells, how it is clinically used, for example, in matrix assisted autologous chondrocyte transplantation. Beneath primary differentiated cells, today different progenitor or stem cells are in the focus for tissue engineering applications, because there is hope that these cells proliferate and differentiate by help of various soluble signals [15]. On the level of clinical application or on the level of clinical trials, there are already different examples of several combinations from biomaterials, incorporated bioactive molecules or preceding of cells respectively. A prime example for the use of a biomaterial combined with cells are preceded synthetic polymeric vascular grafts, which is already well known for more than a decade [16], or interconnecting porous hydroxyapatide loaded with BMP-2 for osteoblast growth, and differentiation to support fracture healing [17]. The up-coming use of signaling molecules and growth factors passed into the next step of evolution, namely the concept of guided tissue engineering. The future developments will show, if this concept has to be characterized as a paradigm change. The aim of guided tissue engineering is to induce cell proliferation, not only within a used scaffold but also to attract cells, especially progenitor cells from the surrounding tissue to invade in the damaged tissue, to proliferate and differentiate in this location. An important idea behind this aim is that with the attraction of cells from the surrounding tissue, the scaffold or cell-scaffold-construct became really integrated in the damaged tissue. With that issue, one of the first problems of biomaterial use could be approached; the interface-problem of implantations, which is evident since their first use back in history. If the proper use of active agents, biomaterials and cells could create a complete integrated construct within the damaged tissue, then regeneration of a structural and functional new tissue will be possible. The view to the historical development makes clear that, on the one hand, there is a growing complexity in the field of tissue engineering but that on the other hand, this complexity could lead to clinical applications for tissue engineering strategies. To reach this goal, further aspects should be taken into account: with the modern tissue engineering properties which give important input to morphogenesis, the current in vitro models tends to be not more two-dimensional but three-dimensional, with heterotopic cell interactions under different biochemical or physico-mechanical conditions. For a better understanding of the third dimension during morphogenesis under these conditions, nondestructive analytical methods such as $\mu$-CT or synchrotron $\mu \mathrm{CT}$ will become more and more attractive, and new algorithms will be established $[18,19]$. Furthermore, getting deeper in the understanding of morphogenesis and its role for tissue regeneration, we have to take into account that many in situ models are animal models and that there are critical differences in wound-healing, differentiation and progenitor cell biology, so that we have to prove if a special animal model fits really for the human situation [13]. Therefore, the request for human in situ models will become an innovative challenge. This is a fascinating field for the pathologist [20] and is closely related to the question of proper scientific use of surplus tissue, and a state of the art biobanking in the clinic [21]. With regard to human in situ analyses, both adult and embryological tissue is of tremendous value and therefore, the ethical and juridical feasibilities and boundaries, should be further discussed. Nevertheless, animal models will be necessary also in the future times for the proof of principal in innovative new biomaterial developments. For the clinical perspective, the evaluation of tissue engineering strategies will be of special importance; since only by the systematic survey of tissue engineering strategies, there performance could be proofed and optimized. Therefore, the recent European survey on cellular and engineered tissue therapies gives an extraordinary example for the recording of extend and indications of such therapies, and the cellular components used already in the clinic [22]. In this context, the anatomic-pathological re-evaluation of tissue 
Citation: Brochhausen C, Kirkpatrick CJ (2012) An Evolutionary View on Guided Tissue Engineering-from the Replacement to the Regeneration of Damaged Tissue. J Tissue Sci Eng 3:e117. doi:10.4172/2157-7552.1000e117

engineering applications could give further information regarding the morphogenetic properties, and the long-term performance of such strategies. For these purposes, clinicians, pathologists and scientists should interact to develop recommendations for the indication and performance of bioptical analyses. These strategies could help to bring, even more tissue engineering stratefies into the clinic, and may help to anchorage them for patient care. In this context, it will be the debate of the future in what extent we will further need preceded scaffolds, or if active molecule loaded smart materials will be sufficient to stimulate regeneration in the damaged area, which means that the body would become its own bioreactor. To introduce such solutions into the clinic, we live for this ongoing fascinating challenge - to regenerate critical tissue defects!

\section{References}

1. Alfieri A, Strauss C, Meller $H$, Stoll-Tucker B, Tacik P, et al. (2012) The woman of Pritschoena: an example of the German neolithic neurosurgery in SaxonyAnhalt. J Hist Neurosci 21: 139-146.

2. Piek J, Lidke G, Terberger T (2011) The Neolithic skull from Bölkendorf-evidence for Stone Age neurosurgery? Cent Eur Neurosurg 72: 42-43.

3. Thurston AJ (2007) Paré and prosthetics: the early history of artificial limbs. ANZ J Surg 77: 1114-1119.

4. Minozzi S, Fornaciari G, Musco S, Catalano P (2007) A gold dental prosthesis of Roman imperial age. Am J Med 120: e1-e2.

5. Richards RG, Moriarty TF, Miclau T, McClellan RT, Grainger DW (2012) Advances in Biomaterials and Surface Technologies. J Orthop Trauma

6. Harris JD, Siston RA, Pan X, Flanigan DC (2010) Autologous chondrocyte implantation: a systematic review. J Bone Joint Surg Am 92: 2220-2233.

7. Kirkpatrick CJ, Fuchs S, Peters K, Brochhausen C, Hermanns MI, et al. (2006) Visions for regenerative medicine: interface between scientific fact and science fiction. Artif Organs 30: 822-827.

8. Holzapfel BM, Reichert JC, Schantz JT, Gbureck U, Rackwitz L, et al. (2012) How smart do biomaterials need to be? A translational science and clinical point of view. Adv Drug Deliv Rev.

9. Aida T, Meijer EW, Stupp SI (2012) Functional supramolecular polymers Science 335: 813-817.
10. Bessa PC, Casal M, Reis RL (2008) Bone morphogenetic proteins in tissue engineering: the road from laboratory to clinic, part II (BMP delivery). J Tiss Eng Reg Med 2: 81-96.

11. Reddi $\mathrm{AH}$ (2000) Morphogenesis and tissue engineering of bone and cartilage: inductive signals, stem cells, and biomimetic biomaterials. Tissue Eng 6: 351 359.

12. Brochhausen C, Lehmann M, Halstenberg S, Meurer A, Klaus G, et al. (2009) Signalling molecules and growth factors for tissue engineering of cartilage-what can we learn from the growth plate? J Tissue Eng Regen Med 3: 416-429.

13. Brochhausen C, Zehbe R, Watzer B, Halstenberg S, Gabler F, et al. (2009) Immobilization and controlled release of prostaglandin E2 from poly-L-lactideco-glycolide microspheres. J Biomed Mater Res A 91: 454-462.

14. Watzer B, Zehbe R, Halstenberg S, James Kirkpatrick C, Brochhausen $C$ (2009) Stability of prostaglandin E(2) (PGE (2)) embedded in poly-D,L: -lactideco-glycolide microspheres: a pre-conditioning approach for tissue engineering applications. J Mater Sci Mater Med 20: 1357-1365.

15. Pilz GA, Ulrich C, Ruh M, Abele H, Schäfer R, et al. (2011) Human term placenta-derived mesenchymal stromal cells are less prone to osteogenic differentiation than bone marrow-derived mesenchymal stromal cells. Stem Cells Dev 20: 635-646.

16. Deutsch M, Meinhart J, Fischlein T, Preiss P, Zilla P (1999) Clinical autologous in vitro endothelialization of infrainguinal ePTFE grafts in 100 patients: a 9-year experience. Surgery 126: 847-855.

17. Kaito T, Myoui A, Takaoka K, Saito N, Nishikawa M, et al. (2005) Potentiation of the activity of bone morphogenetic protein-2 in bone regeneration by a PLAPEG/hydroxyapatite composite. Biomaterials 26: 73-79.

18. van Lenthe $\mathrm{GH}$, Hagenmüller $\mathrm{H}$, Bohner M, Hollister SJ, Meinel L, et al. (2007) Nondestructive micro-computed tomography for biological imaging and quantification of scaffold-bone interaction in vivo. Biomaterials 28: 2479-2490.

19. Zehbe R, Riesemeier H, Kirkpatrick CJ, Brochhausen C (2012) Imaging of articular cartilage--data matching using $X$-ray tomography, SEM, FIB slicing and conventional histology. Micron 43: 1060-1067.

20. Brochhausen C, Schmitt V, Bittinger F, Kirkpatrick CJ (2008) Acute appendicitis as an in situ model to analyse the dynamic processes of peritoneal inflammation. Pathologe 29 1: 83.

21. Sarojini S, Goy A, Pecora A, Suh SK (2012) Proactive biobanking to improve Research and Health care. J Tissue Sci Eng 3: 116

22. Martin I, Baldomero H, Bocelli-Tyndall C, Passweg J, Saris D, TyndallA (2012) The survey on cellular and engineered tissue therapies in Europe in 2010. Tiss Eng Part A. 